\title{
DA POSSIBILIDADE DE IMPLEMENTAÇÃO DE NORMAS SOCIAIS PROGRAMÁTICAS PELO PODER JUDICIÁRIO: ANÁLISE DE VIABILIDADE
}

Rafael José Nadim de Lazari ${ }^{1}$

\section{RESUMO}

Através dos métodos lógicos, dedutivo e comparativo, este artigo discute a polêmica questão do constitucionalismo contemporâneo brasileiro, sobre a viabilidade de implementação de normas sociais programáticas, especificamente na forma de políticas públicas, pelo Poder Judiciário. Assim, será impossível fugir, ao longo do estudo, da discussão sobre ativismo judicial, mínimo existencial e reserva do possível, bem como a questão envolvendo o desrespeito alegado à separação de funções nesta atividade implementadora. No final, será dado um parecer valorativo, com proposta de entendimento sobre o tema.

Palavras-chave: Normas sociais programáticas. Políticas públicas. Separação de funções. Ativismo judicial. Mínimo existencial.

\section{ABOUT THE POSSIBILITY OF IMPLEMENTATION OF SOCIAL PROGRAMMATIC NORMS BY JUDICIARY: VIABILITY ANALYSIS}

\begin{abstract}
Through logical, deductive and comparative methods, article discusses controversial question of contemporary constitutionalism brazilian, about the viability of implementation of social programmatic norms, specifically in the form of public policies, by Judiciary. So, will be impossible to flee, throughout the study, of the discussion about judicial activism, existential minimum and reserve of possible, as well as the question involving the alleged disrespect in the separation of functions in this implementation activity. In the end, will be given a valorative opinion, with proposal by an understanding about the theme.
\end{abstract}

\footnotetext{
1 Advogado, consultor jurídico e parecerista. Mestrando-bolsista (CAPES-PROSUP Modalidade 1) em Direito pelo Centro Universitário "Eurípides" de Marília/SP - UNIVEM. Pesquisador do Grupo de Iniciação Científica "Novos Rumos do Processo de Conhecimento", sob orientação do Prof. Dr. Gelson Amaro de Souza. Colaborador permanente de diversos periódicos especializados de Direito.E-mail: rafa_scandurra@hotmail.com
} 
Key-words: Social programmatic norms. Public policies. Separation of functions.Judicial activism. Existential minimum.

\section{Linhas prolegominais}

“Ativismo judicial”, expressão em voga que ecoa com retumbância pelos corredores do Judiciário brasileiro. O que antes não passava de decisões isoladas - pontualmente proferidas, vale lembrar -, e devidamente discutidas nas cátedras jurídicas, ganha fidalgos contornos de mesmice se considerada a frequência com que têm se dado. Mas, devidamente instruído com o jargão popular de que a diferença entre o veneno e o remédio é apenas a dosagem, há se atentar para um risco de excessos por parte do julgador. Com efeito, há muito mais por trás do "ativismo judicial" que a simples atividade criadora do juiz. É o que pretendemos, modestamente, desvendar.

E é assim que o artigo começa. Com um claro posicionamento restritivo, ab initio, à intervenção do Judiciário. Mas, que não se crucifique sem prévio julgamento este que vos escreve, afinal, não que defendamos o retorno ao gendarmerismo estatal, mas critérios precisam ser instituídos. Critérios, e não a mera adaptação moderna do "método Robin Hood" de tirar do Estado, "rico", para dar ao povo, "pobre", determinando que se cumpra, não importa como, com que dinheiro, e com qual planejamento, em troca de um estado de consciência, digamos, tranquilo, por parte do julgador.

A Constituição Federal, nascida fisicamente aos cinco de outubro de 1988, mas ideologicamente muito antes, em 1976, com a Constituição da República Portuguesa ${ }^{2}$, é digna de elogios na comunidade internacional, como uma Carta, apesar de prolixa, definidora de direitos e garantias fundamentais, numa refundação de um novo Brasil, livre dos grilhões ditatoriais e das entranhas do assistencialismo barato que marcou o populismo dos governos latino-americanos em décadas anteriores.

\footnotetext{
${ }^{2}$ Concorda-se, pois, com as palavras de Ana Carolina Lopes Olsen (2008, p. 249): "É inegável, a influência que a Constituição Portuguesa de 1976 exerceu na Constituição Federal de 1988, especialmente na positivação de direitos fundamentais sociais $[\ldots] "$
} 
Mas, o que era para ser ponto germinante de grandes e positivas transformações sobejantes na vida social dos por ela tutelados, esbarrou na crise do Estado de bem-estar, incapaz em atender a todas às promessas propostas na Lei Maior pátria ${ }^{3}$.

E o constituinte tem culpa por ter sido eufórico demais ${ }^{4}$. Fazendo uma análise superficial do conjunto de normas constitucionais garantistas, e não meramente reguladoras, é ululante, hoje, que não são nem nunca foram passíveis de cumprimento pleno. Para se ter uma ideia, a título ilustrativo, o art. $1^{\mathrm{o}}$ da Constituição Federal traz os "fundamentos da República Federativa do Brasil", dentre os quais a cidadania (II) e a dignidade da pessoa humana (III). Depois, o art. $3^{\circ}$ da aludida Carta traz os "objetivos fundamentais da República Federativa do Brasil”, como construir uma sociedade livre, justa e solidária (I), bem como promover o bem de todos (IV). Em seguida, o art. $5^{\circ}$ traz direitos e deveres individuais e coletivos em nada menos que setenta e oito incisos, com um parágrafo primeiro que afirma que "as normas definidoras dos direitos e garantias fundamentais têm aplicação imediata". Também, o art. $6^{\circ}$ traz outro rol de direitos sociais, como a educação, a saúde, o trabalho e a moradia. Isso sem contar os princípios constitucionais sensíveis do art. 34, VII e todo o Título VIII, da Lei Maior, que trata da ordem social.

Clarividente, neste diapasão, a técnica de "cláusulas abertas", genéricas, adotada pelo constituinte de 1988, possibilitando ampla margem de interpretação pelo aplicador do direito, seja este na condição de Agente Executivo, definidor e implementador de políticas públicas típico, ou de Agente Judiciário, na condição de solucionador de demandas via provocação de interessados e implementador de políticas públicas atípico.

\footnotetext{
${ }^{3}$ Neste sentido, as palavras de Arno Arnoldo Keller (2007, p. 155): "Fala-se muito em "crise do Estado social", que atinge os direitos sociais, para cuja realização se exige a prestação efetiva dos serviços que ao Estado competem. Entretanto, por falta de garantias jurídicas apropriadas para exigir tal cumprimento acabou ficando ao alvedrio dos detentores do poder e, consequentemente, crescem cada vez mais a dívida social, a absurda desigualdade da distribuição de renda, com o consequente distanciamento cada vez maior entre os mais e os menos favorecidos em todos os níveis".

${ }^{4}$ Opinião nossa. Em sentido contrário, Andreas J. Krell (2002, p. 26): "Na Alemanha, como no Brasil, se reconhece que promessas constitucionais exageradas mediante Direitos Fundamentais Sociais sem a possibilidade real de sua realização são capazes de levar a uma "frustração constitucional" (Verfassungsenttäuschung), o que acaba desacreditando a própria instituição da constituição como sistema de normas legais vigentes e pode abalar a confiança dos cidadãos na ordem jurídica como um todo. No entanto, a frustração e desconfiança que essas proclamações solenes, carentes de eficácia, possam provocar não autoriza a abordar essa questão em termos de um utopismo ingênио oи um voluntarismo irreflexivo. (grifei)
} 
O problema é que, dentre os direitos constitucionalmente previstos, garantiu-se o acesso à justiça e a inafastabilidade do Judiciário, o que fez com que as pessoas passassem a procurar a função julgadora em prol da minimização de suas mazelas sociais. Mas isso já é tema para o capítulo seguinte.

\section{Os direitos sociais na Constituição Federal}

"Sociedade" (art. 30, I), "valor social do trabalho e da livre iniciativa" (art. 1", IV), "integração social" (art. 4, P.U), "função social" (art. 5, XXIII), "direito social" (art. 6º), "assistência social" (art. 203), "comunicação social" (art. 220) etc., são alguns exemplos de quão imbuída está a Carta Magna de 1988 destes direitos ditos sociais, e cujo ponto de maior concentração reside no Capítulo II, do Título II, da Constituição Federal, constitutivo de espécie dos Direitos e Garantias Fundamentais, e objetivo fundamental da República Federativa do Brasil (art. $3^{\circ}$, III, parte final, CF). Não é à toa que a Carta Magna pátria é chamada "Constituição Dirigente"

Tamanha a importância dos direitos sociais para o constituinte que, no preâmbulo constitucional, ainda que de maneira não-intencional, foram sensivelmente colocados antes dos direitos individuais ${ }^{6}$, o que denotou preocupação de fraternidade do legislador nas tratativas pós-ditatoriais.

Interessante notar que o Capítulo I, do Título II, da Constituição, trata dos "direitos e deveres individuais e coletivos", coisa que não se repete no Capítulo subsequente do mesmo Título, quando se fala de "direitos sociais", apenas, e não de "direitos e deveres sociais", o que

\footnotetext{
${ }^{5}$ Cf. Miguel Calmon Dantas (2009, p. 51): “A Constituição brasileira de 1988 é dirigente. Ser dirigente pode expressar muito ou quase nada, pois tal qualidade não implica necessariamente que as direções e os programas constitucionais previstos, desde o art. $1^{\circ}$, passando pelos objetivos fundamentais do art. $3^{\circ}$ e chegando aos objetivos e fundamentos da ordem econômica no art. 170, traduzam-se em realidade".

6 Preâmbulo constitucional: "Nós, representantes do povo brasileiro, reunidos em Assembleia Nacional Constituinte para instituir um Estado Democrático, destinado a assegurar o exercício dos direitos sociais e individuais, a liberdade, a segurança, o bem-estar, o desenvolvimento, a igualdade e a justiça como valores supremos de uma sociedade fraterna, pluralista e sem preconceitos, fundada na harmonia social e comprometida, na ordem interna e internacional, com a solução pacífica das controvérsias, promulgamos, sob a proteção de Deus, a seguinte Constituição da República Federativa do Brasil". (grifei).
} 
leva a crer numa sociedade predominantemente destinatária e não emitente de direitos assecuratórios de sua qualidade de vida.

Isso dá uma natureza prestacional e eminentemente positiva aos direitos sociais, de segunda dimensão, diferentemente daqueles ligados à liberdade, de primeira dimensão, de cunho negativo sobejante ${ }^{7}$. Neste sentido, oportunas as palavras de Dimitri Dimoulis e Leonardo Martins (2008, p. 67):

Nada obstante, as prestações estatais (dimensão objetiva) que realizam os direitos sociais podem ser de duas espécies. Primeiro, podem ser prestações materiais (na terminologia alemã "ações fáticas positivas" - positive faktische Handlungen) que podem consistir no oferecimento de bens ou serviços a pessoas que não podem adquiri-los no mercado (alimentação, educação, saúde etc.) ou no oferecimento universal de serviços monopolizados pelo Estado (segurança pública). Segundo, podem ser prestações normativas (na terminologia alemã "ações normativas positivas" - positive normative Handlungen) que consistem na criação de normas jurídicas que tutelam interesses individuais.

Ademais, além das considerações acima expostas quanto aos direitos sociais, há se somar a influência histórica das Constituições Zapatista, de 1917, e de Weimar, de 1919, da Declaração Universal dos Direitos Humanos, de 1948, e do Pacto de Direitos Sociais, Econômicos e Culturais de $1966^{8}$, bem como o temor à bem-sucedida Revolução Bolchevique do lado oriental do mapa ${ }^{9}$, para poder, enfim, concluir que os direitos sociais consistem em

\footnotetext{
${ }^{7}$ Cf. Dimitri Dimoulis e Leonardo Martins (2008, p. 65) acerca dos direitos de primeira dimensão: “A essência do direito está na proibição imediata de interferência imposta ao Estado. Trata-se de um direito negativo, pois gera a obrigação negativa endereçada ao Estado de deixar de fazer algo. Trata-se de uma obrigação de abster-se da intervenção na esfera de liberdade garantida pela Constituição (imperativo de omissão - Unterlassungsgebot). $\mathrm{O}$ termo que melhor qualifica essa categoria de direitos é o termo "pretensão de resistência à intervenção estatal" e de forma abreviada, "direito de resistência". Com isso, traduz-se a designação desses direitos feita na doutrina constitucional alemã feita pelo termo Abwehrrechte.

${ }^{8}$ Cf. Vidal Serrano Nunes Júnior (2009, p. 52-55): “A Carta mexicana, refletindo esse ideário de bem-estar social, promoveu a constitucionalização dos direitos de proteção do trabalho [...]. A evolução dos direitos sociais foi sucessivamente marcada pela Constituição de Weimar de 1919, que, a seu modo, consubstanciou significativos avanços no campo dos direitos fundamentais, que serviram de inspiração para diversas Constituições posteriores [...]. Além disso, a Declaração de 1948 buscou um amplo reconhecimento dos direitos sociais [...], na medida em que consolida a noção de direitos sociais como direitos intrínsecos à natureza humana, apontados, portanto, como de observância necessária por todos os Estados do mundo. Pode-se afirmar, nesse sentido, que esse conteúdo fortemente impregnado de direitos sociais da Declaração de 1948 deu lugar, em 1966, ao Pacto Internacional sobre Direitos Sociais, Econômicos e Culturais, que constitui uma espécie de desdobramento, de complementação, dos princípios antes adotados por aquela.

${ }^{9}$ Elemento por nós acrescido. Com a derrota nazi-fascista e a bipolarização do mundo entre os EUA, capitalista, e a URSS, comunista, bem como a destruição da Europa pela Segunda Grande Guerra, acirrou-se a disputa para angariar adeptos para um ou outro bloco. Assim, não se pode dizer que a benevolência social nas Constituições
} 
prestações afirmativas do Estado, que sai de seu mero dever liberal - e muito cômodo, diga-se de passagem - de abstenção, para entrar na vida de seus tutelados.

Isto posto, sem mais delongas, para efeito de delimitação temática e teleologia prática, este artigo se concentra no polo irradiador de direitos sociais para toda a Constituição Federal ${ }^{10}$, qual seja, o art. $6^{\circ}$, que afirma serem direitos sociais a educação, a saúde, a alimentação, o trabalho, a moradia, o lazer, a segurança, a previdência social, a proteção à maternidade e à infância, e a assistência aos desamparados, ou seja, tudo que se prevê no aludido dispositivo constitucional é absoluto dever do estado, que deve efetivá-lo, p. ex., com a construção e ampliação de escolas, creches, hospitais, centros de saúde e casas populares, concessão de benefícios de assistência social e seguro-desemprego, zelo para a não-obsolescência da segurança pública etc. (enfim, as tais "políticas públicas”).

Mas, dois problemas nevrálgicos decorrem da previsão constitucional de direitos sociais $^{11}$.

O primeiro deles, de ordem econômica, consiste no fato de serem os direitos sociais extremamente problemáticos aos cofres públicos porque, apesar de dispendiosos, são geralmente destinados a atender a um interesse individual e não coletivo ${ }^{12}$, o que faz com que escolhas de interesse predominante necessitem ser feitas ${ }^{13}$, desde que respeitado um mínimo

ocidentais pós-Segunda Guerra tenha se dado por mera influência ideológica socialista/comunista, mas pelo temor do avanço da "Cortina de Ferro".

${ }^{10}$ Isso em nada diminui o conteúdo abrangido pelo estudo, afinal, a título ilustrativo, a mesma educação que é genericamente tratada no art. $6^{\circ}$, também o é, de forma específica, nos arts. 205 a 214, da Constituição, tal qual a relação entre a saúde do art. $6^{\circ}$ e o que se prevê entre os arts. 196 e 200 da Carta de 1988.

${ }^{11} \mathrm{Na}$ Alemanha, a Lei Fundamental de Bonn, de 23 de maio de 1949, optou por excluir de seu conteúdo os direitos sociais, a despeito do que fez, trinta anos antes, a Constituição de Weimar. Neste diapasão, apropriadas as palavras de Andreas J. Krell (2002, p. 46): "Os modernos artigos da Carta de Weimar sobre direitos sociais foram "ridicularizados" por parte dos integrantes da extrema-direita e esquerda política, como "promessas vazias do Estado burguês" e "contos de lenda". Como consequência, o legislador fundamental de 1949 renunciou deliberadamente à formulação de normas que conferem direitos subjetivos a prestações positivas por parte do Estado. Os direitos sociais, cuja eficácia sempre depende de vários fatores econômicos e políticos, ficaram de fora". Neste sentido, complementa o autor (2002, p. 46): "A maioria dos autores alemães se dirige contra Direitos Fundamentais Sociais na constituição, porque estes seriam, na sua maioria, não realizáveis na atualidade por parte do Estado, provocando a impressão do cidadão de que todo o texto constitucional seria nada mais do que uma "construção de frases" ou um "catecismo popular, cheio de utopias" que resultaria na perda da normatividade da Carta e da sua força de estabelecer valores". (grifei).

${ }^{12}$ Cf. Wladimir Brega Filho (2002, p. 23).

${ }^{13}$ Daniel Sarmento (2010, p. 392), em análise à obra de Guido Calabresi e Philip Bobbit, fala da expressão "escolhas trágicas" utilizada pelos autores: "A escassez obriga o Estado em muitos casos a confrontar-se com verdadeiras "escolhas trágicas", pois, diante da limitação de recursos, vê-se forçado a eleger prioridades dentre 
existencial de cada cidadão ${ }^{14}$. Sendo assim, é inexigível ao Estado que cada brasileiro tenha uma casa para morar, ou que a rede pública forneça todos os medicamentos possíveis para todas as enfermidades, ou que a segurança pública seja desempenhada de maneira profícua e suficiente. Disso decorre a chamada Reserva do Possível, com berço no Tribunal Constitucional Federal alemão, em 1973, que, como já dito alhures, deve respeitar o "mínimo".

Sobre a "reserva", já opinou Ana Carolina Lopes Olsen (2009, p. 199-200):

[...] a reserva do possível determina que um direito só poderá ser exigido dentro das condições fáticas existentes. Todavia, a partir desta noção, verifica-se certa insegurança na doutrina e na jurisprudência quando se faz necessária uma referência à reserva do possível, sendo que alguns tratam-na como princípio, outros como cláusula ou postulado, e outros são mais específicos ao tratá-la como condição de realidade [...]. Diante desse quadro parece mais adequado tratar exclusivamente de "reserva do possivel", como uma condição da realidade que influencia na aplicação dos direitos fundamentais. (grifei).

Ante o acima mencionado infere-se que, por "reserva do possível", entende-se o reconhecimento honroso estatal de sua incapacidade em atender às necessidades ilimitadas da população, dados seus recursos, limitados. Para maximizar esforços e ampliar resultados, o Estado se utiliza de auxiliares, como quando se vale da concessão, permissão e autorização de serviços públicos (art. 175 e seguintes, CF), quando recebe auxílio do chamado "Terceiro Setor", e quando permite a exploração, pela iniciativa privada, de algumas dessas atividades, como o ensino privado (art. 197, CF) e a saúde particular (art. 195).

várias demandas igualmente legítimas. Melhorar a merenda escolar ou ampliar o número de leitos na rede pública? Estender o saneamento básico para comunidades carentes ou adquirir medicamentos de última geração para o tratamento de alguma doença rara? Aumentar o valor do salário mínimo ou expandir o programa de habitação popular? Infelizmente, no mundo real nem sempre é possível ter tudo ao mesmo tempo

${ }^{14}$ Vidal Serrano Nunes Júnior $(2009$, p. 72) explica o "mínimo": "O chamado conteúdo mínimo aponta que cada direito tem um núcleo mínimo irremissível, associado à sua própria razão de ser. Evoca, assim, uma abstração que enuncia a essência do direito cogitado, que não pode ser objeto de supressão ante qualquer panorama histórico ou ante quaisquer eventuais limites. Já o chamado mínimo vital opera com vetores quantitativos, ou seja, aponta quais as necessidades mínimas que um ser humano, se por sê-lo e exatamente para preservá-lo em sua dignidade, deve observar". 
Já o segundo destes problemas, de ordem jurídica, decorre da questão de muitos destes direitos sociais terem sido trazidos à Constituição Federal na condição de normas constitucionais programáticas ${ }^{15}$ e 16 .

Em que pese a importância do problema de ordem política, este artigo vai se debruçar especialmente sobre o segundo cerne da questão, de ordem jurídica, a partir do próximo capítulo.

\section{Sobre a possibilidade de implementação de normas sociais programáticas pelo Poder Judiciário}

O "disparo motivador" para a elaboração do presente artigo foram algumas decisões exaradas no âmbito do Supremo Tribunal Federal, determinando o atendimento em creche e pré-escola para crianças de até seis anos de idade, com supedâneo no art. 208, IV, da Constituição Federal, dispositivo corolário lógico do direito social à educação, como já visto (vide nota explicativa ${ }^{\circ} 9$ ), previsto no art. $6^{\circ}$ da aludida Carta ${ }^{17}$. Vejamos:

CONSTITUCIONAL. ATENDIMENTO EM CRECHE E PRÉ- SCOLA. I. - Sendo a educação um direito fundamental assegurado em várias normas constitucionais e ordinárias, a sua não-observância pela administração pública enseja sua proteção pelo Poder Judiciário. II. - Agravo não provido.

\footnotetext{
${ }^{15}$ Cf. Miguel Calmon Dantas (2009, p. 267): “A nota típica das constituições que fixam objetivos e tarefas para o Estado quanto ao contexto social e econômico, como também no respeitante dos direitos fundamentais em geral, especialmente aos direitos sociais, é a feição programática".

${ }_{16} \mathrm{O}$ conceito de "normas constitucionais programáticas" é basicamente o mesmo, apesar das diversas classificações de normas constitucionais. Crisafulli apud André Ramos Tavares (2003, p. 85), p. ex., fala em normas constitucionais auto-aplicáveis e normas dependentes de complementação, sendo estas últimas subdivididas em normas de legislação e normas programáticas. Já Zagrebelsky apud André Ramos Tavares (2003, p. 85-86) faz a classificação em normas de eficácia direta e indireta, sendo estas últimas divididas em normas de eficácia diferida, normas de princípio e normas programáticas. Em síntese, por "normas programáticas" entendese: "aquelas em que o legislador, constituinte ou não, em vez de editar regra jurídica de aplicação concreta, apenas traça linhas diretoras, pelas quais se hão de orientar os poderes públicos. A legislação, a execução e a própria justiça ficam sujeitas a esses ditames, que são como programas dados à sua função". (Pontes de Miranda apud Luís Roberto Barroso, 2000, p. 117).

${ }^{17}$ A ideia do artigo surgiu da leitura da obra de Elival da Silva Ramos (Ativismo Judicial: parâmetros dogmáticos. São Paulo: Saraiva, 2010), mais especificamente o item 27 (p. 264-267), da Seção II, que trata exatamente do problema. Tal fato levou este autor que vos escreve à pesquisa doutrinária e jurisprudencial objetivando desenvolver o tema.
} 
(RE 463210 AgR, Relator(a): Min. CARLOS VELLOSO, Segunda Turma, julgado em 06/12/2005, DJ 03-02-2006 PP-00079 EMENT VOL-02219-11 PP-02181 RT v. 95, n. 849, 2006, p. 199-202 RMP n. 31, 2009, p. 187-191) (grifei).

RECURSO EXTRAORDINÁRIO - CRIANÇA DE ATÉ SEIS ANOS DE IDADE ATENDIMENTO EM CRECHE E EM PRÉ-ESCOLA - EDUCAÇÃO INFANTIL DIREITO ASSEGURADO PELO PRÓPRIO TEXTO CONSTITUCIONAL (CF, ART. 208, IV) - COMPREENSÃO GLOBAL DO DIREITO CONSTITUCIONAL À EDUCAÇÃO - DEVER JURÍDICO CUJA EXECUÇÃO SE IMPÕE AO PODER PÚBLICO, NOTADAMENTE AO MUNICÍPIO (CF, ART. 211, $\S 2^{\circ}$ ) - RECURSO IMPROVIDO. [...] - Essa prerrogativa jurídica, em conseqüência, impõe, ao Estado, por efeito da alta significação social de que se reveste a educação infantil, a obrigação constitucional de criar condições objetivas que possibilitem, de maneira concreta, em favor das "crianças de zero a seis anos de idade" (CF, art. 208, IV), o efetivo acesso e atendimento em creches e unidades de pré-escola, sob pena de configurar-se inaceitável omissão governamental, apta a frustrar, injustamente, por inércia, o integral adimplemento, pelo Poder Público, de prestação estatal que lhe impôs o próprio texto da Constituição Federal. - A educação infantil, por qualificar-se como direito fundamental de toda criança, não se expõe, em seu processo de concretização, a avaliações meramente discricionárias da Administração Pública, nem se subordina a razões de puro pragmatismo governamental. [...] - Embora resida, primariamente, nos Poderes Legislativo e Executivo, a prerrogativa de formular e executar políticas públicas, revela-se possível, no entanto, ao Poder Judiciário, determinar, ainda que em bases excepcionais, especialmente nas hipóteses de políticas públicas definidas pela própria Constituição, sejam estas implementadas pelos órgãos estatais inadimplentes, cuja omissão - por importar em descumprimento dos encargos políticojurídicos que sobre eles incidem em caráter mandatório - mostra-se apta a comprometer a eficácia e a integridade de direitos sociais e culturais impregnados de estatura constitucional. A questão pertinente à "reserva do possível". Doutrina. (RE 410715 AgR, Relator(a): Min. CELSO DE MELLO, Segunda Turma, julgado em 22/11/2005, DJ 03-02-2006 PP-00076 EMENT VOL-02219-08 PP-01529 RTJ VOL00199-03 PP-01219 RIP v. 7, n. 35, 2006, p. 291-300 RMP n. 32, 2009, p. 279-290) (grifei).

Com efeito, quando se disse, no final do capítulo anterior, acerca do problema de direitos sociais constarem em normas constitucionais programáticas, isto se dá em razão da latente discussão doutrinária quanto à possibilidade de atravessamento, pelo Poder Judiciário, em detrimento do Executivo, com fito de minimizar a esfera de ingerência desta função.

Para Elival da Silva Ramos (2010, p. 266), se está diante de claro exemplo de "ativismo judicial”, mas opina o autor pela impossibilidade de efetivação de normas sociais programáticas pelo Poder Judiciário:

Não é dado ao Poder Judiciário definir, discricionariamente, o nível de eficácia de norma constitucional, em sede de direitos fundamentais ou não. Se a análise dos elementos interpretativos pertinentes, com destaque, na espécie, para os de ordem 
sistemática, histórica e teleológica, bem como, secundariamente, para os dados extraídos da realidade material, indica a natureza programática da norma-matriz, não é lícito à Corte Constitucional, sob o argumento da fundamentalidade do direito nela expresso, conjugando com referências genéricas ao princípio da força normativa, ignorar a opção prescritiva adotada, inequivocamente, pela Constituição, a qual torna dependente de providências integrativas de amplo espectro (que vão da formulação de políticas públicas adequadas à sua cabal execução, abrangente de medidas legislativas, administrativas - normativas e não normativas - e orçamentárias) a implementação efetiva do direito comparado.

Em complemento, o autor (2010, p. 267) chega a expressar seu temor, nos desencadeamentos que podem derivar-se desta decisão pelo STF:

O que se poderia especular é se o Pretório Excelso estenderá essa jurisprudência ativista, por ora localizada, a outros direitos sociais prestacionais associados a normas programáticas, como é o caso dos direitos à moradia e de assistência aos desamparados. (grifei).

Por outro lado, é majoritária a doutrina pela qual age corretamente o Judiciário em sua empreita. É este o entendimento de Luís Roberto Barroso (2000, p. 146), pelo qual a potencialidade dos direitos sociais não pode ser desperdiçada, a mercê da boa vontade regulamentadora dos Poderes Públicos:

Foi demonstrado no local próprio [...] que existem na Constituição verdadeiros direitos sociais, conceptualmente qualificáveis como direitos subjetivos, tutelando bens e interesses pronta e diretamente exigíveis. Muitos deles já se tornaram plenamente efetivos [...]. Outros, no entanto, deixam de concretizar-se, muito embora sejam veiculados em dispositivos que apresentam a mesma estrutura lógico-normativa das demais regras definidoras de direitos, comportando aplicação direta e imediata. É que, injustificadamente, tem-se desperdiçado a enorme potencialidade de preceitos aptos a proporcionar o desfrute de bens e interesses de proveito individual e coletivo.

Como justificativa, defende o autor (2000, p. 154-156) que existe, sim, desde sua previsão, conteúdo eficaz nas normas constitucionais programáticas:

Por fim, vejamos em que limites as normas programáticas são diretamente aplicáveis. [...] Tais normas, como já se viu, investem os indivíduos em posição jurídica menos consistente que as da segunda categoria - a das normas definidoras de direitos. É que, por não traçarem suficientemente uma conduta a ser seguida, não ensejam um desfrute imediato de qualquer bem jurídico, criando a exigibilidade de uma prestação positiva. Sem embargo, elas conferem, por via reflexa, direitos subjetivos de caráter negativo, direta e imediatamente exigíveis, amparáveis em sede judicial. Sistematizando a doutrina acerca da matéria, que converge para o reconhecimento do teor de eficácia jurídica das normas programáticas, é possível elencar algumas hipóteses de sua efetividade, visto que as regras desta natureza: (1) revogam as leis anteriores com 
elas incompatíveis; (2) vinculam o legislador, de forma permanente, à sua realização; (3) condicionam a atuação da administração pública; (4) informam a interpretação e aplicação da lei pelo Poder Judiciário. Contêm as normas constitucionais programáticas, por via de consequência, eficácia paralisante de todos os atos que não sejam reverentes às proposições acima formuladas e facultam ao jurisdicionado o reconhecimento e declaração de sua inconstitucionalidade [...]. Concluindo este tópico, deixa-se anotado, como ponto para reflexão futura, que em certos casos, ainda carentes de sistematização, é possível invocar uma norma constitucional programática para impor ao Poder Público determinada obrigação de fazer. Em outras palavras: existem hipóteses que comportam, por parte dos legitimados, a exigibilidade de determinadas prestações positivas. (grifei).

Noutro argumento desse posicionamento majoritário, Arno Arnoldo Keller (2007, p. 232) parte para o entendimento de que deve ser superada a denominação "normas programáticas", tudo em prol de um constitucionalismo dirigente ${ }^{18}$ :

Estão superadas as opiniões doutrinárias divergentes acerca da espécie de normas que instituem os direitos sociais nas constituições dos Estados sociais. O constitucionalismo do Estado social evidenciou o entendimento da força normativa da Constituição, o valor dos princípios e da materialidade da Constituição. É a Constituição dirigente que supera a denominação de "normas programáticas" ou "normas compromissárias", traz um novo paradigma de interpretação dos textos constitucionais. Os direitos sociais positivados nas constituições constituem-se em obrigações positivas, o que lhes confere a característica da exigibilidade ${ }^{19}$.

Por fim, Vidal Serrano Nunes Júnior (1999, p. 77) acena para essa possibilidade em sua doutrina, quando o constituinte conferiu ao povo direitos subjetivos em face do Estado, bem como instrumentos para se alcançá-los:

Assim, boa parte das constituições modernas optou por conformá-los como parte do ideário estatal, fixando programas de realização paulatina e à mercê da vontade política e administrativa da governança de cada Estado. A insuficiência dessas previsões e a conclusão incontornável de que, ao menos em alguns aspectos essenciais, os direitos sociais não poderiam vicejar das variações das disputas políticas de momento fizeram com que se projetassem novas formas de contemplá-los. Como anunciado, alguns países em que esta é a única forma de positivação, como a

\footnotetext{
${ }^{18}$ Sobre "constitucionalismo dirigente", ver nota explicativa $\mathrm{n}^{\circ} 4$.

${ }^{19}$ Em mesmo sentido, Andreas J. Krell (2002, p. 37-38): "Conforme disposto no $\S 1^{\circ}$ do art. $5^{\circ}$ da Constituição Federal, as normas sobre Direitos Fundamentais são de aplicação imediata. Encontramos regulamentações semelhantes nas Cartas de Portugal [...] e da Alemanha [...], que certamente inspiraram a Constituinte nacional. Esse dispositivo serve para salientar o caráter preceptivo e não programático dessas normas, deixando claro que os Direitos Fundamentais podem ser imediatamente invocados, ainda que haja falta ou insuficiência de lei”. Também, Ana Carolina Lopes Olsen (2008, p. 249): “A doutrina da Constituição Dirigente provocou a superação da noção de Constituição programática, sem eficácia vinculante, e determinou uma inversão paradigmática da interpretação das normas constitucionais: elas passaram a ser o fundamento das normas infraconstitucionais, as quais deveriam ser lidas e interpretadas à luz da Constituição, e não o contrário".
} 
Alemanha, optaram por desenvolver noções como a de limiar mínimo em matéria social; outros países, como o Brasil, sem prejuízo de formulações como esta, optaram por plasmar disposições auto-aplicáveis, investindo os cidadãos em direitos subjetivos, frente ao Estado, ao lado de outros mecanismos de previsão e proteção desses direitos. (grifei).

Em apertada síntese, então, se está diante de dois posicionamentos diametralmente opostos, quais sejam, aquele que entende pela impossibilidade de implementação de normas sociais programáticas pelo Poder Judiciário, dada a necessidade de respeito à separação de funções e o olhar com ressalvas à força normativa da Constituição; e aquele que ventila permissivamente a isso, em razão do dirigencialismo constitucional, do conteúdo potencialmente eficaz destas normas, e da conferência, pelo constituinte, de instrumentos de busca de direitos subjetivos, inclusive sociais, em 1988.

Em que pese o respeito aos dois posicionamentos supramencionados, nenhum dos dois goza de razão absoluta.

Em primeiro lugar, há se desmistificar a ideia de uma distinção clara e patente entre as três funções, previstas constitucionalmente no art. $2^{\circ}$. Nesta frequência, oportunas, a princípio, as palavras de Andreas J. Krell (2002, p. 90):

O Estado Social moderno requer uma reformulação funcional dos poderes no sentido de uma distribuição que garanta um sistema eficaz de freios e contrapesos, para que a separação dos poderes não se interponha como véu ideológico que dissimule e inverta a natureza eminentemente política do direito. Na medida que as leis deixam de ser vistas como programas condicionais e assumem a função de programas finalísticos, o esquema clássico da divisão dos poderes perde sua atualidade.

Ora, bem se sabe que o poder é uno, na condição de poder estatal, e cujas funções, legislativa, executiva e judiciária, constituem-no e efetivam-no ${ }^{20}$. Sendo assim, a bem de um poder estruturalmente ajustado, como as engrenagens de uma máquina, cujas peças dependem umas das outras, podem as funções problemáticas ser auxiliadas por aquela que, momentaneamente, melhor desempenho possui. Do contrário, pensando em funções cuja esfera de atuação não se pode invadir, ter-se-ia uma função imperfeita, não auxiliável por outra, o que

\footnotetext{
${ }^{20}$ Concordamos com Karl Loewenstein (1970, p. 55), quando afirma que o correto seria o termo "separação de funções", vez que a expressão "poderes", apesar de institucionalizada, deve ser entendida de maneira figurativa.
} 
acabaria por deixar o poder também imperfeito, dado o desajuste entre as engrenagens mencionadas alhures.

Ademais, o tempo é cíclico, e se outrora falou-se em politização da justiça, os tempos hodiernos são de judicialização da política. E isso não deve ser visto como uma imperfeição, afinal, houve um tempo em que o Judiciário não gozava de autonomia suficiente para considerar-se equiparado às demais funções. Os próprios excertos de Aristóteles, e mais tarde, de Montesquieu, não conferiam essa autonomia ao judiciário ${ }^{21}$.

Desta forma, não há se falar em separação de funções, de maneira absoluta e intransponível. Se admite-se que o Legislativo auxilie o Judiciário, como ocorreu com a Emenda Constitucional $n^{\circ} 45 / 2004$; se admite-se que o Executivo auxilie o Judiciário, como quando aumenta a dotação de verbas orçamentárias; não deve ser vista como aberração a interferência excepcional do Judiciário como implementador de políticas públicas, ainda que contidas programaticamente.

E, por falar em Judiciário, convém traçar algumas linhas sobre "ativismo judicial”, sobre o qual principiamos o estudo. Com efeito, há que se reafirmar que o ativismo é muito mais que a mera atividade de criação do juiz. Isto porque, uma decisão judicial pode ser mais traiçoeira do que se imagina, sobretudo pensando no "efeito dominó" que ela pode causar. Aqui tem razão Elival da Silva Ramos, conforme citado alhures, quando teme que, no rastro de uma decisão que determina o atendimento em creche e pré-escola a crianças numa determinada faixa etária, se pleiteie junto ao Judiciário o direito social à moradia, afinal, foi-se o tempo em que normas sociais programáticas tinham conotação política ${ }^{22}$.

Que isso não signifique, entretanto, que se obste o Judiciário, indistintamente, implementar tais espécies de normas. Mas que o faça com critérios, elementos que confeririam ao fenômeno boa dose de racionalidade, colocando fim ao mero estado de consciência do

\footnotetext{
${ }^{21}$ Cf. Karl Doehring (2008, p. 284-285): "Entretanto, Montesquieu via aqui somente uma questão de menor valor, que certamente não representava uma dificuldade propriamente dita. Ele descrevia a justiça como "en quelque façon nul" e como "la bouche de la loie", onde expressão que o exercício do Poder Judiciário não faz parte dos órgãos estatais, cuja formação política e jurídica incumbe ao Estado [...]"

${ }_{22}$ As normas sociais programáticas com conotação política ganharam o desprezo da doutrina constitucionalista majoritária, dada a carência de efetividade destas, condicionadas à boa-vontade dos agentes públicos, obstruídas pela burocracia e falta de planejamento. Neste sentido, Andreas J. Krell (2002, p. 20): "Outros autores não aceitam a expressão normas "programáticas", visto que, no passado, essa foi utilizada para enfatizar um pretenso caráter não jurídico e meramente político das mesmas, com a finalidade de criar um bloqueio para sua efetividade".
} 
julgador que costuma nortear estas decisões. Daí o posicionamento restritivo tomado no início do trabalho, que pode ter levado muitos a crer que se estava defendendo um Judiciário nãointerventivo.

Mas, que tipo de critérios?

Após a realização de audiências públicas no tentame de definir métodos viáveis de fornecimento de medicamentos, o STF proferiu decisão, na Suspensão de Tutela Antecipada $n^{\circ}$ 175/178, envolvendo a União e o município de Fortaleza/CE, estabelecendo, ainda embrionariamente, os seguintes parâmetros: 1) Em primeiro lugar, é preciso observar se a política pública que preveja o fornecimento do medicamento existe ou não. Caso exista, mas não esteja em aplicabilidade, é perfeitamente possível ao Poder Judiciário determinar sua implementação, afinal, não estará intervindo em área de atuação que não a sua, tão menos “criando-a", conforme se critica; 2) Por sua vez, caso a política não exista, passa-se ao segundo questionamento, consistente em saber se o Sistema Único de Saúde fornece medicamento/tratamento potencialmente similar ao pleiteado. Se positiva a resposta, que se determine o fornecimento do medicamento símile; 3) Se inexiste o medicamento/tratamento é preciso saber se isto se dá por injustificada omissão administrativa ou se há motivação para seu não-fornecimento. Se a norma social potencial não for materializada pela mera inércia do agente, legitimado estará o Poder Judiciário a determinar o fornecimento do medicamento, por conta do direito constitucional à saúde, assegurado no art. 196 e seguintes, da Constituição Federal, e em razão do conteúdo jurídico das normas sociais programáticas (vide nota explicativa $\mathrm{n}^{\circ}$ 21). Agora, se houver motivação fundada do Sistema Único de Saúde para não fornecer o medicamento, como sua proibição pela ANVISA - Agência Nacional de Vigilância Sanitária, apesar de possível no exterior, impedido estará o Judiciário de interferir.

Observa-se, pois, que a decisão tomada pelo Guardião da Constituição Federal imbuiuse de racionalidade, não se fundando exclusivamente na força normativa da Constituição nem na Dignidade da Pessoa Humana, mas também em preceitos capazes de conferir um senso de justiça e conformação às partes litigantes. Por certo, não é dado ao Judiciário saber de onde, exatamente, virá o custeio do que se lhe requer, portanto, que se prolate decisões pautadas pelo equilíbrio, em que se evidencie o sopesamento de valores e o destemor de saber acatar ou negar com veemência um pedido, ainda que a questão seja "de vida ou morte". 
Nos julgados trazidos logo no início do capítulo, sobre atendimento em creche e préescola a crianças de determinada faixa etária, sob manto do direito social à educação, questionamentos poderiam ter sido feitos, como a existência ou não de instituições deste tipo no município, razões por sua não existência, qualidade das estruturas existentes e razões por sua eventual obsolescência, o possível abarrotamento de crianças em detrimento da carência de funcionários suficientemente aptos a prestar-lhes os devidos cuidados etc. Tais fatos poderiam melhor embasar uma decisão a apaziguar os ânimos de vencedores e vencidos na peleja judicial.

Critérios. É preciso critérios.

\section{Linhas derradeiras: proposta em prol de um entendimento}

Por todo o explanado nestas poucas linhas, convém reafirmar algumas premissas básicas que foram ditas ao longo deste ensaio:

1) $\mathrm{O}$ ativismo judicial é mais que mera atividade criadora do juiz. É preciso precaução contra reações adversas que podem derivar de uma decisão dita ativista, sob pena de consubstanciação de verdadeira injustiça: concede-se, criativamente, a um, mas não a outro no futuro, ao perceber-se o efeito colateral causado pela decisão anterior;

2) Os direitos sociais são direitos fundamentais de segunda dimensão, com aspecto eminentemente positivo, decorrentes do Estado de bem-estar, espalhados por todo o ordenamento constitucional pátrio, mas cujo polo irradiador reside no art. $6^{\circ}$, Constituição Federal;

3) Grande parte dos direitos sociais estão previstos em normas constitucionais programáticas, e, em razão disso, há quem diga que não possa o Judiciário intervir em políticas públicas, determinando sua materialização, dado o respeito à separação de funções e à relativização da força normativa da Constituição; enquanto, por outro lado, predomina o entendimento pelo qual, em razão do dirigencialismo constitucional, da necessária superação das normas programáticas, e da conferência de instrumentos ao povo, de busca de direitos subjetivos, poderia, sim, o Poder Judiciário efetivar normas sociais programáticas;

4) Não se confere razão absoluta a nenhum dos dois entendimentos, em que pese o respeito por tais. Com efeito, defende-se a adoção de critérios, parâmetros, métodos, que o 
julgador deve seguir quando da prolação de sua decisão, inviabilizando-se pronunciamentos unicamente de cunho subjetivo (lembremos que vivemos o sistema do livre convencimento motivado), pautadas apenas na consciência e no estado de espírito de quem decide. O exemplo a ser seguido é o que fez o Supremo Tribunal Federal, na Suspensão de Tutela Antecipada n ${ }^{\circ}$ 175/178, envolvendo a União e o município de Fortaleza/CE, quando levantou-se questionamentos para a determinação de fornecimento de medicamentos pelo Judiciário, após a realização de audiências públicas.

Em suma, pois, retirando da decisão do julgador sua exclusividade subjetiva, e preenchendo os vazios com parâmetros firmes, tal qual vem tentando fazer a hermenêutica constitucional, indubitável será a sintonia alcançada, no controle de políticas públicas, entre as funções estatais.

Não custa repetir: Critérios. É preciso critérios.

\section{REFERÊNCIAS BIBLIOGRÁFICAS}

BARROSO, Luís Roberto. O direito constitucional e a efetividade de suas normas: limites e possibilidades da Constituição brasileira. 4. ed. Rio de Janeiro: Renovar, 2000.

BREGA FILHO, Vladimir. Direitos fundamentais na Constituição de 1988: conteúdo jurídico das expressões. São Paulo: Editora Juarez de Oliveira, 2002.

DANTAS, Miguel Calmon. Constitucionalismo dirigente e pós-modernidade. São Paulo: Saraiva, 2009.

DOEHRING, Karl. Teoria do estado. Belo Horizonte: Del Rey, 2008.

DIMOULIS, Dimitri; MARTINS, Leonardo. Teoria geral dos direitos fundamentais. São Paulo: RT, 2008.

GRIMM, Dieter. Constitucionalismo y derechos fundamentales. Madrid: Editorial Trotta, 2006. 
KELLER, Arno Arnoldo. A exigibilidade dos direitos fundamentais sociais no estado democrático de direito. Porto Alegre: Sergio Antonio Fabris Editor, 2007.

KRELL, Andreas J. Direitos sociais e controle judicial no Brasil e na Alemanha: os descaminhos de um direito constitucional "comparado”. Porto Alegre: Sergio Antonio Fabris Editor, 2002.

LOEWENSTEIN, Karl. Teoria de la Constitución. 2. ed. Barcelona: Ed. Ariel, 1970.

NUNES JÚNIOR, Vidal Serrano. A cidadania social na Constituição de 1988: estratégias de positivação e exigibilidade dos direitos sociais. São Paulo: Verbatim, 2009.

OLSEN, Ana Carolina Lopes. Direitos fundamentais sociais: efetividade frente à reserva do possível. Curitiba: Juruá, 2008.

QUEIROZ, Cristina M.M. Direitos fundamentais (teoria geral). Coimbra: Coimbra Editora, 2002.

RAMOS, Elival da Silva. Ativismo judicial: parâmetros dogmáticos. São Paulo: Saraiva, 2010.

SARMENTO, Daniel. A proteção judicial dos direitos sociais: alguns parâmetros ético-jurídicos In Leituras complementares de direito constitucional: direitos humanos e direitos fundamentais. 4. ed. Salvador: JusPODIUM, 2010.

SUPREMO TRIBUNAL FEDERAL. www.stf.jus.br. Acesso em 28/11/2010

TAVARES, André Ramos. Curso de direito constitucional. 2. ed. São Paulo: Saraiva, 2003.

VADE MECUM RT. 5. ed. São Paulo: RT, 2010. 